Fontes , M. and Sousa, C. (2016),Types of proximity in knowledge access by science-based start-ups, European Journal of Innovation Management, Vol. 19 Iss 3 pp. 298 - 316, http://dx.doi.org/10.1108/EJIM-10-2014-0104

\title{
Types of proximity in knowledge access by science-based start-ups
}

\section{Margarida Fontes}

Laboratório Nacional de Energia e Geologia (LNEG), Lisbon, Portugal and Instituto Universitário de Lisboa (ISCTE-IUL), DINÂMIA'CET-IUL, Lisboa, Portugal

\section{Cristina Sousa}

Instituto Universitário de Lisboa (ISCTE-IUL), Lisboa, Portugal and DINÂMIA'CET-IUL, Lisboa, Portugal
Abstract:
Purpose
The paper addresses the strategies adopted by science-based start-ups to gain access to knowledge resources at diverse spatial levels. It investigates the presence and relative importance of ties endowed with different types of proximity in firms' knowledge networks, and the role played by non-geographical proximity in gaining access to knowledge sources, both nearby and distant.
Design
An analytical framework is proposed distinguishes between two dimensions of proximity - geographical and relational - leading to different forms of proximity that are further linked with modes of knowledge interaction (formal or informal). A methodology for network reconstruction is developed and applied to Portuguese molecular biology firms, permitting to identify the origin, location and nature of the ties and to position them along forms of proximity.

\section{Findings}
The results show that the incidence and mix of the different forms of proximity vary in firms' individual networks, being possible to identify several patterns. They also uncover the relevance of relational proximity, whether or not coexisting with geographical proximity and often compensating for its absence.

\section{Originality}
The paper contributes to the literature on the role of proximity in knowledge access, by developing and empirically testing a taxonomy of forms of proximity that takes in consideration the characteristics of science-based firms. It uncovers the mechanisms through which relational proximity can contribute to span spatial boundaries, highlighting the role played by entrepreneurs' personal networks. It also offers insights into the knowledge strategies adopted by science-based firms located outside the main concentrations of knowledge in their field. 


\section{Keywords:}

knowledge networks; space; relational proximity; science-based firms; formal and informal ties; entrepreneurs trajectory

\section{Introduction}

Biotechnology is frequently presented as example of an industry whose mode of organization spans several spatial levels. In fact, research has shown that biotechnology firms tend to cluster around major centres of knowledge production and/or key clients (Aharonson et al., 2007), but also that they are frequently highly internationalized, engaging in a variety of relationships with organizations located around the world (Owen-Smith and Powell, 2004).

This is namely the case in what concerns knowledge access. Biotechnology firms are often created to exploit knowledge originating from scientific research and they frequently act as intermediaries between academic research and commercial applications (Murray, 2004; Stuart et al., 2007). Thus, high-level scientific capabilities in a fast changing field are at the root of firms' competitiveness and good connections with knowledge sources, wherever these are located, are critical to achieve it (Owen-Smith and Powell, 2004). As a result, firms' knowledge networks will often combine relationships characterized by geographical proximity, with relationships where such proximity does not exist. The need to connect to organizations in geographically distant locations can be particularly pressing for firms located outside the major concentrations of knowledge production in biotechnology (Fontes, 2005; Gilding, 2008). Thus biotechnology start-ups in this type of location are a particularly interesting setting to address the relevance of proximity in knowledge access.

Recent research has extend the concept of proximity beyond the geographical boundaries; and has started to address the role of non-geographical forms of proximity social, cognitive, organizational - on knowledge exchange (Breschi and Lissoni, 2001; 
Boschma, 2005; Brockel and Boshma, 2012). However there still is a limited understanding of how individual firms combine geographical and non-geographical proximity in their knowledge access strategies. Similarly, there is still limited knowledge on whether and how firms use these other forms of proximity to gain access to knowledge sources located at a geographical distance, whose access is recognized to entail greater difficulties (Bathelt et al., 2004). Finally, we also do not know whether the type of proximity to knowledge sources has implications for the nature of the relationships established with them.

This paper addresses these gaps. The goal is to understand the networking strategies adopted by science-based firms to gain access to knowledge at different spatial levels, and the role played by non-geographical proximity in such access. Thus, we investigate the presence and relative importance of relations endowed with different types of proximity, in the knowledge networks of biotechnology start-ups created in a relatively peripheral location. In addition we also attempt to achieve a better understanding of the nature of these relationships, by investigating whether different types of proximity are associated with specific modes of interaction, formal or informal. Because research organizations are the key (and sometimes only) external source of scientific and technological knowledge in these firms' early years (McMillan et al., 2000), we focus on the relationships established with them.

For this purpose we build an analytical framework that distinguishes between two dimensions of proximity: geographical, related with the spatial location of the source; relational, associated with the origin of the relationship. Combining these dimensions we propose a taxonomy of forms of proximity. This framework is applied to the empirical analysis of the networks established by Portuguese biotechnology start-ups to access knowledge from research organizations. 
The paper contributes to literature on the role of proximity in knowledge access in two ways. At a conceptual level, by bringing into the proximity debate insights from the social network and entrepreneurship literature, in order to develop a taxonomy of forms of proximity that takes in consideration the characteristics of science-based firms. At an empirical level, by assessing the relative importance of different forms of proximity in firms' knowledge networks and, in particular, by uncovering the mechanisms through which relational proximity can contribute to span spatial boundaries. The research adds to our understanding of the strategies adopted by science-based start-ups to gain access to knowledge at different spatial levels, highlighting the role played by entrepreneurs' personal networks.

\section{Knowledge Access by Science-Based Firms}

New biotechnology firms are knowledge-intensive companies that derive their competitiveness from the capacity to quickly expand and renew their knowledge base, in order to generate a steady stream of innovations (Owen-Smith and Powell, 2004). However, because they tend to be small firms, such competitiveness also depends on the ability to gain access to knowledge originating from external sources, in particular from research organizations (Levitte and Bagchi-Sen, 2010; McMillan et al., 2000). Given firms' specialized requirements and the distributed nature of the knowledge production in biotechnology, knowledge sources can be very diverse and located all around the world (Gertler and Levitte, 2005; Whittington et al., 2009).

Research on the knowledge strategies of new biotechnology firms has shown that the process of identification and access to key knowledge sources, as well as the process of admittance to the circles where knowledge circulates and alliances are built, rely strongly on 
entrepreneurs' social networks (McKelvey et al., 2003; Murray, 2004; Owen-Smith and Powell, 2004; Fontes, 2005). Thus, new firms establish a set of knowledge-related relationships that can facilitate access to key knowledge sources. These encompass personal relationships built by the entrepreneurs along their academic and professional trajectory (Saxenian and Hsu, 2001; Burton et al., 2002); and new linkages established, already at firm level, with strategic purposes (Hite and Hesterly, 2001; Sousa and Fontes, 2014).

Those relationships may be kept informal or be formalized through some type of contract. Thus firms' knowledge networks are usually composed of formal and informal ties, which can be closely interlinked (Gulati, 1998). Firms have been found to establish formal relationships with both the "parent" organization, and other research organizations that enable them to keep abreast of advanced knowledge production (McMillan et al., 2000; Levitte and Bagchi-Sen, 2010). Research on informal knowledge networks is scarce, particularly when it comes to networking between firms and research organizations (Kreiner and Schultz, 1993; Østergaard, 2009). According to the literature, informal network formation is usually linked with the trajectory of individuals or with their previous interaction in formal partnerships (Smith-Doerr and Powell, 2003), and loyalty and reciprocity are fundamental for the continuity of the relationships (Dahl and Pedersen, 2004). They are often described as geographically localized (Audretsh and Stephan, 1996; Huggins and Johnston, 2010) although some authors observed their operation at different spatial levels (Trippl et al., 2009).

The composition of the knowledge networks of individual firms is determined by their specific knowledge requirements, which vary, according to the nature of firms' knowledge base and the business opportunity being exploited (Moodysson et al., 2008; Conceição et al., 2012). However, the search for the knowledge necessary to fulfil these requirements is influenced by the location of relevant sources and thus, their spatial scope greatly depends on 
the knowledge environment where firms operate (Whittington et al., 2009; Vissers and Dankbaar, 2013). In addition, the quality of the entrepreneurs personal networks is also determinant, as they can have an important role in guaranteeing access to some sources (Elfring and Hulsink, 2003; Murray, 2004). Thus, both the location of knowledge sources and the conditions in which these can be accessed are expected to influence the spatial distribution of firms' knowledge networks.

\section{Proximity, Networks and Knowledge Access}

The evidence on the geographical location of biotechnology firms' knowledge sources is mixed. Biotechnology start-ups are often described as strongly dependent on knowledge originating from the "parent" organization, locating in its vicinity and establishing close relationships with it (Grandi and Grimaldi, 2003; Lemarié et al., 2001). However, it is also argued that the significance of these links depends on the characteristics of firms and the knowledge assets searched (Audretsch and Stephan, 1996; Mangematin et al., 2002). The complexity and frontier nature of the knowledge being exploited by many biotechnology firms may require them to search for knowledge wherever it is available (Cooke, 2006; Gertler and Levitte, 2005). Firms created outside the main "biotechnology centres" may need to resort more extensively (and more precociously) to geographically distant sources (Fontes, 2005; Gilding, 2008).

This means that biotechnology firms' knowledge networks will often combine relationships characterized by geographical proximity and relationships where such proximity does not exist. It is therefore important to understand the implications of this spatial distribution. 
The importance of geographical proximity for knowledge exchange has been extensively discussed. The social networks literature stresses its relevance, since the development and continuity of ties require intense and frequent interactions (Stuart and Sorenson, 2003). The economic geography literature argues that learning processes are strengthened by a close interaction between actors who exchange information and knowledge (Lorenzen. 2007; Healy and Morgan, 2012). Geographical proximity is regarded as particularly relevant when knowledge has a strong tacit component. In biotechnology this often occurs in the case of new scientific discoveries, characterized by "natural excludability" (Zucker et al., 2002).

Recent research has criticized the excessive emphasis put on geographical proximity per se and uncovered some of the mechanisms that are behind the greater ease in knowledge exchanges among co-located actors (Breschi and Lissoni, 2001; Boschma, 2005). It has been shown that underneath the importance attributed to geographical proximity lies the role played by co-location in the creation of other forms of proximity - social, cognitive and organizational - that effectively facilitate knowledge transmission. Social proximity is important because it eases communication and generates trust (Burt, 1997). Some degree of cognitive proximity is necessary to assess the value of the knowledge produced and to fully understand it, as well as to absorb and apply it effectively (Cohen and Levinthal, 1990). Moreover, a combination of social and cognitive proximity may be required to be part of the "epistemic communities" of scientists that are often the locus for knowledge sharing in science-based fields (Breschi and Lissoni, 2001). Finally, organizational proximity (previous or actual) facilitates interaction, since it enables an understanding of the rules, hierarchies and codes of behaviour that prevail in a given organization. 
These forms of proximity often result from the frequent face-to-face interaction and experience sharing enabled by co-location (Torre and Rallet, 2005). Thus, the ability to fully profit from them is enhanced when the actors are co-located (Healy and Morgan, 2012; Vissers and Dankbaar, 2013). This partly explains why firms may prefer to establish knowledge relationships with organizations that are geographically close (Aharonson et al., 2007). However, as pointed out by Torre (2008), those effects may also be at least partly achieved through temporary co-location of individuals. As such, the actual organizations do not necessarily need to be co-located. In fact, while co-location may be a condition for the creation of these types of proximity, the capacity to maintain and benefit from them does not require continued physical proximity (Fontes, 2005). Relationships endowed with social and/or cognitive proximity can persist after the individuals draw apart, supporting subsequent knowledge exchanges at a distance (Saxenian and Hsu, 2001; Oettl and Agrawal, 2008).

It is exactly the persistence of relational effects over time and space that can explain the operation, at a distance, of some of the mechanisms described by the proximity literature as facilitating knowledge exchange. These effects may be especially relevant in the case of relationships with organizations located outside country borders, whose establishment may involve greater barriers, given differences in institutional contexts (McKelvey et al., 2003). In the particular case of science-based start-ups, the growing international mobility of the scientific community offers would-be entrepreneurs opportunities for the development of persistent relationships encompassing social and cognitive elements (Fontes et al., 2013) that can be subsequently mobilized by their firms (Williams et al., 2004).

\section{A Framework to Examine the Role of Proximities in Knowledge Access}


So, when addressing the knowledge networking strategies of new biotechnology firms, it is necessary to take into account both geographical proximity and other forms of proximity. Moreover, the above discussion suggests that the presence of these other forms of proximity with knowledge sources (irrespective of their location) is likely to be a significant element in the knowledge search decisions of biotechnology entrepreneurs. It is therefore important to understand whether this is effectively the case; and the extent to which entrepreneurs rely on non-geographical proximity in the building-up of their knowledge networks at different spatial levels.

The empirical literature on knowledge and proximity already identified an association between the occurrences of these other forms proximity, individually or in combination, and the presence of knowledge relationships between organizations (Nooteboom et al., 2007; Ponds et al., 2007; Broekel and Boschma, 2012). However, this literature does not address firms' decisions on the activation of these forms of proximity, neither the eventual differences between firms in such activation. This paper addresses this gap, by investigating the presence and relative importance of relationships endowed with different types of proximity in the knowledge networks of biotechnology start-ups.

One additional problem concerns the operationalization of the non-geographical forms of proximity, which can be complex (Boschma, 2005) and has, in many cases, been object of relatively rough approximations. In this paper we propose, drawing on the social network and entrepreneurship literature, that in the case of the knowledge relationships established by science-based start-ups, the trajectories of entrepreneurs can be instrumental to uncover the presence of non-geographical proximity.

According to this literature, the personal networks built by the entrepreneurs along their previous academic and professional path are critical for firm creation and early 
development, being extensively used by them to obtain key resources (Burton et al., 2002; Newbert and Tornikoski, 2012). If we consider the formation of these personal networks at the light of the above discussion, we observe a process whereby entrepreneurs' permanence in one or more organizations permitted the (temporary) co-location between individuals and thus the development of relationships between them. This created the conditions for the development of social and, in some circumstances, also cognitive proximity. In addition, permanence in a given organization may have enabled entrepreneurs to gain a better understanding of its culture and routines.

Following this reasoning, it is possible to argue that the personal networks connecting entrepreneurs with organizations from their trajectory are likely to encompass at least some of the forms of proximity that facilitate knowledge transmission. This approach enables us to operationalize non-geographical proximity, for the case of start-up firms, relating it with the presence of this type of previous relationship with a knowledge source.

As a result, we define two main dimensions of proximity: geographical, related with the spatial location of the knowledge source; and relational, related with the origin of the tie. Drawing on these dimensions, we develop a framework to analyze the knowledge networks that link biotechnology start-ups and research organizations. According to this framework, the ties (relations) that compose these firms' networks can have diverse origins and encompass diverse spatial levels. The combination of these dimensions can lead to a taxonomy of "forms of proximity" (Figure 1):

- Ties can result from the mobilization of entrepreneurs' pre-existing personal network. These ties can be established with actors who are in the vicinity of the firm, and thus involve both geographical and relational proximity. If those ties are established with actors who are geographically distant, they will only involve relational proximity. 
- Ties can be based on a purposeful effort to develop new relationships with actors that possess knowledge regarded as critical, but with whom there was no previous involvement and thus, no relational proximity was developed. These actors can be in the vicinity of the firm and thus ties will involve only geographical proximity. If not, we are in the presence of distant ties, both in geographic and relational terms.

Figure 1

The nature of the ties mobilized for knowledge access may also differ: relations can be formalized or be kept informal. The social network literature leads us to expect that new purposefully built ties are more frequently formalized, because trust does not exist from the outset (Lorenz, 1999); while it is more likely to be already present in the case of trajectory ties (Burt, 1997). In addition, the cluster literature suggests that local ties may be easier to sustain in an informal mode, given the opportunity for frequent interactions that act as trust enhancer and facilitate the control for opportunism (Dahl and Pedersen, 2004); while geographically distant relationships may require the additional glue of contractual agreements. Thus, the nature of the ties that prevail in each category of proximity (or their specific combination) may differ. Therefore, formal and informal ties will be also considered in the framework, along with the different forms of proximity, as shown in Figure 1.

This framework will base our approach to the main objectives of this paper:

(1) To investigate the presence and relative importance of relationships endowed with different forms of proximity in the knowledge networks of science-based firms;

(2) To investigate whether firms profit from relational proximity to gain access to knowledge sources, both located nearby and/or located at distance;

(3) To investigate whether different types of proximity are associated with specific modes of interaction, formal or informal. 
The variety of behaviour among individual firms also needs to be taken into account. It is acknowledged that firms have different relational mixes in their knowledge networks (Lowe and Gertler, 2009). Because firms may also differ concerning the spatial availability of the required knowledge, and the conditions for gaining access to it, their networks are also likely to display different "proximity mixes". So, an additional objective is:

(4) To assess whether it is possible to identify patterns of proximities (i.e. combinations of different forms of proximity) at the level of individual firms' networks.

\section{Research Setting and Methodology}

The research uses the case of Portuguese biotechnology industry as empirical setting, addressing the networks established by new firms to access knowledge from research organizations. The analysis focuses on starting-up firms, thus encompassing the period of "firm formation", which is assumed to be a process that includes the pre-start-up period, the year of formal creation and the two subsequent years of activity.

Portugal developed a reasonable knowledge base in biotechnology and has gone through a process of scientific internationalization, but still has obvious limitations in terms of amount and variety of autonomous knowledge production. A biotechnology industry has already emerged, but is still in a relatively incipient stage of development. For these reasons, the case of Portugal is a particularly interesting setting to address the different proximity dimensions of firms' knowledge access strategies, in a multi-spatial context.

\subsection{Description of Sample}

The analysis focuses on the most science-based sub-set of the Portuguese 
biotechnology industry: firms whose activities are based on the development/application of molecular biology, encompasses 23 out of the 25 firms identified in Portugal in this field at the time of the research. These firms were selected from a proprietary database on Portuguese biotechnology firms, systematically compiled by the authors since 1998. The identification of a "molecular biology" sub-group was supported by two field experts. Only two of the firms classified in this sub-group were unavailable to participate in the research, thus the sample covered almost all the known population.

This group of firms belongs to the younger generation of biotechnology companies: only three were over five years old at the time of data collection, and about half were still in the "formation period" as defined above. The oldest firms belong to the small group of biotechnology pioneers, established before changes in the institutional and political environment created a more favourable environment for this type of companies (Fontes, 2007). Firms' activities are mainly concentrated in the health sector (78\%), although predominantly outside the biopharmaceutical industry (which only accounts for four firms), while a smaller group targets the agro-food sector $(22 \%)$.

Their creation involved a total of 61 entrepreneurs, the vast majority originating from national universities/research centres or returning to the country after completion of PhDs or post-doctorates in foreign organizations. Thus 20 out of the 23 firms were created by teams composed, partly or exclusively of scientists, although some also included individuals with managerial or industrial experience. The firms were usually created by the initiative of young entrepreneurs, but about half also involved at least one senior scientist who, in most cases, retained the university position.

These firms are clustered around the main Portuguese centres of knowledge production in their field. This choice may indicate a decision to create the firm in the vicinity of key knowledge sources, although other motives for location decisions are possible, from 
ease of access to other resources, to personal reasons (Egeln et al., 2004). But if knowledge access was determinant, firms' knowledge networks are expected to include a large proportion of geographically close ties. On the other hand, practically all firms had at least one entrepreneur with an international research trajectory, suggesting that personal networks with foreign research centres could assume a central role in their knowledge search.

\subsection{A Methodology for Network Reconstruction and Analysis}

The empirical research required, first of all, the (re)construction of the networks mobilized for knowledge access during the firm formation period, as well as an assessment of the origin and nature of the ties established with the organizations that composed them.

For this purpose we developed a methodology that combines different data collection methods and sources. Two main types of data were collected: primary data, obtained through face to face interviews with the entrepreneurs; and secondary data, obtained through extensive documentary search on the company and on their founders. The latter included: the Curriculum Vitae of the entrepreneurs, data about formal collaborative projects, partnerships and patents (obtained from public databases), and a variety of documentary information on the entrepreneurs' personal trajectories and on firm formation histories, obtained from diverse sources, ranging from company and institutional websites to the specialized media.

The interviews were based on a semi-structured questionnaire and had two parts. The first focused on the entrepreneurs' personal network and its importance for the start-up process. It allowed the collection of fine grained information about the people who were important during that process, including the origin of the relationships and the type, nature and relevance of their contributions. The second addressed the firm's activities, with particular emphasis on innovation and technology strategies and on firm level relationships. 
The (re)construction of the firms' knowledge networks draw on these sources. First, documentary analysis of $\mathrm{CVs}$, confirmed and complemented by the interviews, permitted to reconstruct the paths of the members of each firm's founding team and to map the organizations where they had developed academic or professional activities and, thus, where personal relationships might have been established. Subsequently, the interviews permitted to identify which of these relationships were effectively mobilized for knowledge access during the firm formation process - these were labelled trajectory ties. On the other hand, the interviews, combined with documentary analysis, permitted to identify the relationships established for knowledge purposes with research organizations that were not part of the entrepreneurs' personal networks - these were labelled intentional ties.

This process permitted to map the set of research organizations that composed the knowledge network of each firm and to identify the origin of the ties that were established with each organization. The data obtained also permitted to distinguish between formal and informal ties. The former included contractual knowledge-oriented relationships established between organizations. The latter included personal, non-formalized relationships between the entrepreneurs and individuals described, during the interview, as important in the process of knowledge access. For operational purposes, informal relationships with individuals were assigned to the organizations to which they belonged. Since, in some cases, firms were found to have both formal and informal relationships with the same organization we defined three types of ties: formal, informal, both formal and informal.

The last step was to assess the level of proximity of each tie, along the two dimensions proposed: geographical and relational. The literature presents several measures of geographical proximity (e.g. Stuart and Sorenson 2003; Ponds et al., 2007). In this research we defined three spatial levels of proximity: local (co-located in the same address or the same 
municipality); national (in a different municipality but within country borders); international (in another country). For relational proximity, we followed the approach defined in the conceptual framework, distinguishing between trajectory ties, which derive from the entrepreneurs' personal networks and are assumed to involve some social, cognitive or organizational proximity; and new intentional ties, where it is assumed that these forms of proximity had no opportunity to develop (Rutten et al., 2010).

\section{Empirical Results: Proximities in Firms' Networks}

In order to answer the questions raised in section 4, the data obtained from the reconstruction of firms' networks was analysed at two levels. In a first step, we assumed the tie as the level of analysis and combined data from all firms, along three variables that correspond to the three tie attributes defined - origin of tie (trajectory, intentional) as proxy to relational proximity; spatial location of source organisation (local, national, international) as proxy to geographical proximity; nature of relationship (formal, informal, both formal \&

informal). Drawing on this data we examined the presence and relative importance of different types of proximity (section 6.1), as well their association with the nature of the relationship (section 6.2), for the whole group of firms. In a second step, we assumed the firm as the level of analysis and searched for patterns in terms of specific combinations of the proximity dimensions (origin and location) in each firm network, using cluster analysis (section 6.3).

\subsection{Relevance of Different Types of Proximity in Knowledge Networks}

In order to investigate the presence and relative importance of the different types of proximity in knowledge access for this group of firms, we draw on the information obtained on each tie, concerning its spatial location and its origin. 
In what concerns the spatial location, Table 1 shows that almost $2 / 3$ of the ties involved non-local organizations, in particular international ones. Thus, even if most firms were located in the vicinity of the main Portuguese centres of knowledge production, ties with local research organizations only represented a subset of their knowledge access activities. Overall, ties with geographically distant knowledge sources were more frequent.

\section{Table 1}

Concerning the origin of these ties - i.e. whether they were related with the entrepreneurs' previous academic or professional trajectory, or were new ties, already built in the context of the firm - Table 2 shows a slight predominance of new ties with organizations that were not present in the previous trajectory of the entrepreneurs and, consequently, where relational proximity was likely to be absent. But trajectory ties, i.e. ties that are close in relational terms, still accounted for a substantial part of the networks of this group of firms.

\section{Table 2}

In order to assess the incidence of the different forms of proximity proposed in our framework, we need to combine the geographical and the relational dimensions of proximity. Thus, we have considered simultaneously the origin and the spatial location of each tie. Regarding the latter we have distinguished between local and extra-local (national and international) ties. Table 3 shows the incidence of ties denoting each form of proximity, for this group of firms.

\section{Table 3}

Surprisingly, distant ties (i.e., ties with neither geographical nor relational proximity) emerge as the most frequent in global terms. However, this high incidence of distant ties is very circumscribed: four firms (of which three "pioneers") concentrate $80 \%$ of these ties, 
which reduces their relevance as compared to ties with some type of proximity. This result is partly explained by the involvement of these firms in European research projects with many foreign partners, external to the entrepreneurs' personal network; even if often accessed through it. In fact, in several cases entrepreneurs mentioned that members of their personal networks had a key role in the access to some of these organizations, thus introducing a relational element in the establishment of the tie. Although we did not explore the case of indirect ties, previous research on Portuguese biotechnology firms documented the presence of such mediation relatively to distant organizations (Fontes, 2005).

About $1 / 4$ of the ties combine geographic proximity with relational proximity, being more frequent than ties with only one kind of proximity. Ties that only involve relational proximity represent $18 \%$. These ties link firms with geographically distant research organizations where entrepreneurs studied or worked, frequently as part of an international scientific trajectory, and to whom they resorted later (activating their personal networks), in order to gain access to knowledge relevant for the firm. Remarkably those ties are more frequent than ties with organization that are geographically close, but with whom there is no relational proximity.

So these results show that the ties that compose the networks mobilized by Portuguese molecular biology firms to access knowledge encompass different forms of proximity, but suggest that a relevant role is played by relational proximity.

\subsection{Types of Proximity and Formal and Informal Relations}

The next step was to understand whether these forms of proximity are associated with different modes of interaction, i.e. whether they differ regarding the relative importance of formal and informal relations. Thus, ties were distinguished in terms of their nature. Table 4 
shows that there is a certain balance between formal and informal ties and that their simultaneous presence in the relationship with a given organization is less frequent.

Table 4

We have subsequently investigated the relationship between forms of proximity and the nature of the ties. Table 5 shows the relative weight of formal, informal or both formal \& informal ties in each category of proximity. Table 6 presents the results of the Spearman (non-parametric) correlation between them.

\section{Table 5}

Table 6

The results show that ties with relational proximity, whether or not combined with geographical proximity, are more frequently informal. Thus, previous shared experiences create the conditions for informal interaction, even with organizations that are geographically distant, in which case the presence of trust may compensate for the less frequent face to face interaction. A still substantial proportion of these ties involve formal and informal interactions, suggesting that trust may not always be enough, given the critical role of knowledge assets for biotechnology firms, and thus some informal relations will need to be formalized (Smith-Doerr and Powell, 2003).

On the contrary, ties that lack relational proximity are more frequently formalized. This is particularly evident for distant ties (both geographically and relationally), but is also the case for ties with only geographical proximity. This contradicts the frequent direct association between co-location and informal exchanges. Rather, it confirms the idea that, at least in what concerns knowledge, informal bartering does not necessarily takes place just because the organizations are co-located, requiring relational proximity to be pursued. In 
addition, the fact that ties with only geographical proximity are sometimes associated with a combination of formal and informal interactions suggests that co-location may favour the creation of informal ties with members of organizations with whom formal relations have been established. As expected, in the case of distant ties - that correspond to new relations with unfamiliar organizations with whom frequent interaction is not possible - formalization appears to be a requirement.

So, the empirical data show that different forms of proximity between science-based start-ups and research organizations are associated with different modes of interaction for knowledge access.

\subsection{Firm-Level Variety in the "Proximity Mix": Patterns of Knowledge Access}

In the previous sections we have considered the tie as the level of analysis and have addressed each form of proximity separately, finding that all of them are present in this group of firms. However, it is expected that each firm mobilizes a particular mix of ties, thus building networks that combine geographical and relational forms proximity. In this section we turn to the firm-level networks and try to identify patterns in what concerns such combinations.

For this purpose, firms were grouped according to the proportion of ties of their network that encompass each of the four forms of proximity: ties with relational \& geographical proximity; ties with relational proximity only; ties with geographical proximity only; distant ties (in both dimensions). A cluster analysis was conducted on these four variables, using the hierarchical cluster procedure with Ward's cluster method and squared Euclidean distance measure. This permitted to discern three different clusters. Figure 2 shows the positioning of these clusters in terms of the proportion of ties with each type of proximity. 
Figure 2

The graph reveals that the networks of firms belonging to different clusters exhibit specific patterns in terms of relative importance of the various forms of proximity. Firms in Cluster 1 are characterized by having a higher proportion of distant ties in their networks; firms in Cluster 3 by having only ties with both forms of proximity; finally firms in Cluster 2 establish more frequently ties with only one type of proximity, either geographical or relational, although also having a significant component of ties with both types of proximity.

Those patterns effectively reflect different strategic behaviours concerning knowledge access. These may be associated with differences in firms' characteristics and knowledge requirements. It is therefore relevant to look in greater detail into the groups of firms composing each cluster.

Cluster 1 concentrates the older firms, created in a period when the Portuguese context was less favourable for biotechnology start-ups. This may partly explain the need to resort extensively to new ties with knowledge sources in distant locations, frequently abroad. Cluster 1 also encompasses all firms active in pharmaceuticals, whose global nature required firms to extend the scope of their knowledge search. Thus, distant ties answered to the need of gaining access to frontier knowledge that was neither available locally, nor in relationally close organizations. Most of the remaining ties involved non-local organizations from the entrepreneur's trajectory, which were instrumental, either directly or as intermediaries to other foreign sources. A high share of these firms was created in the capital region, where research and supportive infrastructures were available earlier and international connections were facilitated.

Firms in Cluster 2 and 3 belong to the younger generation. But they differ concerning the origin of firms' technology, which has implications for the nature of the relationships 
established. All firms in Cluster 3 are research spin-offs created on the basis of technology directly transferred from the parent organization (often a regional university) to which they are co-located and resort extensively, thus establishing ties with dual proximity. These firms adhere closely to the conventional academic spin-off model (Lemarié et al., 2001), reflecting the growing quality and maturity of local research organizations and their interest in promoting entrepreneurial initiatives among staff and students (Fontes, 2007). Conversely, firms in Cluster 2 have more frequently developed the technology in-house, which requires a more diversified set of relationships. Although they also resort extensively to organizations geographically co-located, these are not necessarily part of the entrepreneurs' trajectory. Firms combine these local ties with non-local search, supported by other forms of proximity.

Both firms in Cluster 2 and 3 appear to have benefitted from the development of the science-base in biotechnology and from research organizations' greater willingness to establish collaborative relationships. But Cluster 2 comprises more "footloose" entrepreneurs, including, entrepreneurs who had international trajectories and, upon returning to Portugal, decide to locate their firms in the vicinity of research organizations with a good scientific reputation. However, compared to Cluster 1, they are more strongly anchored on the regions where they create their firms (Vale and Carvalho, 2012), while still maintaining close relationships with foreign organizations from their trajectories. Thus, firms in Cluster 2 appear to be closer to the biotechnology model depicted in the literature - i.e. firms that combine knowledge obtained in their local environment and elsewhere (Whittington et al., 2009) - and use relational proximity to access geographically distant sources.

These results show that even within the relatively homogeneous group of molecular biology firms there is variety, not only in the spatial configuration of firms' knowledge networks as shown in previous research (Mangematin et al., 2002), but also in the proximity- 
mix of the relationships encompassed by them. Differences in the nature of the knowledge being searched can partly explain this variety (Moodysson et al., 2008). But it is also likely to be influenced by the characteristics of the local environment, namely the capacity of the local research organizations to produce advanced knowledge in specific fields (Laursen et al., 2011) and/or to provide or facilitate the connections to relevant sources located elsewhere (McKelvey et al., 2003).

\section{Conclusions}

This paper aimed at contributing to a better understanding of the strategies adopted by science-based start-ups to gain access to knowledge resources at different spatial levels and, in particular, the role played by non-geographical proximity in those strategies.

Previous research has shown that biotechnology knowledge networks tend to combine geographically close and distant relationships. Recent debates on proximity have expanded the concept of proximity, showing that knowledge transmission will often require more than simple co-location, and introducing other types of proximity. But there still is a limited understanding of the relative importance of different forms of proximity in knowledge access by individual firms. In particular, there is limited knowledge on whether and how firms profit from these other types of proximity to gain access to knowledge sources, both located nearby and located at a distance.

In order to address these gaps this paper proposed a taxonomy of forms of proximity that combines two basic dimensions: geographical proximity and "relational" proximity. Since measuring relational proximity can be problematic, the paper draw on the social network and entrepreneurship literature to propose that, at least in the case of science-based start-ups, it could be associated with ties from the entrepreneurs' personal networks, resulting 
from their previous trajectory. The presence and relative importance of different forms of proximity, as well as their eventual association with diverse modes of knowledge exchange (formal or informal), was tested in the networks built by Portuguese biotechnology start-ups to access knowledge from research organizations.

The different forms of proximity proposed were found to be present in the networks of the firms studied. But it was also found that their incidence varies and that firms' networks involve particular combinations of these forms of proximity, being possible to identify some patterns, which were associated with firms' characteristics and environmental conditions.

One key finding of this research concerns the relevance of relational proximity, whether exclusively or coexisting with geographical proximity. It was also found that ties involving relational proximity are more frequently informal, although the relevance of knowledge assets in biotechnology leads firms to formalize some of them. The results also confirm that relational proximity can effectively compensate for geographical distance, and highlight the spatial spanning role of entrepreneurs' personal networks.

However, it was also found that these firms often needed to establish new relationships where, in principle, relational proximity did not have time to develop (Rutten et al., 2010). These ties involve more frequently organizations that are also geographically distant, suggesting that, in the vicinity, entrepreneurs tend to resort more to their personal networks (Huggins and Johnston, 2010). As expected, these ties are more frequently formal (McKelvey et al., 2003). But while formalization is a requirement when relational distance co-exists with geographical distance, it is also present when relational distance co-exists with geographical proximity. This result confirms that simple co-location may not be enough to enable informal knowledge transmission, which requires the additional glue of trust (Dahl and Pedersen, 2004). 
Our findings also show that conditions found in the local environment influence the decision to establish ties with geographically distant research organizations (Gilding, 2008). Among the firms studied, we observe a clear change of orientation between "pioneers", which account for the highest proportion of distant ties, and more recently created firms, which resort more frequently to geographically close sources, reflecting the changes in the capacity of the local context to supply relevant knowledge (Fontes, 2007). But even the latter are often required to expand their search scope. This is not exclusive of firms in more peripheral locations (Owen-Smith and Powell, 2004). But our research has also shown that what differentiates firms in these locations is the fact that their initial knowledge networks already encompass a substantial amount of ties with geographically distant sources, while the literature suggests that the need to resort more extensively to this type of source tends to arise at later stages (McKelvey et al., 2003). Relational proximity, grounded on extensive scientific mobility, was found to be instrumental in those networking processes.

While these results are necessarily influenced by the characteristics of the knowledge environment where the firms studied operate, it can also be argued that these characteristics provided an effective setting to observe the different dimensions of proximity at work. This permitted to uncover their diverse roles on firms' knowledge networking strategies, contributing to the literature on proximity and knowledge access. In addition to these more general contributions, our empirical results are particularly relevant for science-based startups located outside the main concentrations of knowledge in their field. They reflect the networking strategies adopted by this type of firms and provide some insights on the conditions that may facilitate their knowledge access efforts.

This preliminary approach needs now to be complemented with further research that explores those mechanisms in more detail (namely associating them with different types of 
knowledge) and, in particular, that refines the operationalization of relational proximity, by attempting to disentangle the influence of different types of non-geographical proximity. Further research will also explore in greater detail the factors that may explain variety in the proximity-mix of firms' networks.

\section{References}

Aharonson B., Baum J. and Feldman, M. (2007), "Desperately seeking spillovers? Increasing returns, industrial organization and the location of new entrants in geographic and technological space", Industrial \& Corporate Change, Vol. 16 No. 1, pp. 89-130

Audretsch, D.B. and Feldman, M. (1996), "R\&D spillovers and the geography of innovation and production", The American Economic Review, Vol. 86 No. 3, pp. 630-640.

Bathelt, H., Malmberg, A. and Maskell, P. (2004), "Clusters and knowledge: Local buzz, global pipelines and the process of knowledge creation", Progress in Human Geography, Vol. 28 No.1, pp. 31-56.

Boschma, R. (2005), "Proximity and innovation: A critical assessment", Regional Studies, Vol. 39 No. 1, pp. 61-74.

Breschi, S. and Lissoni, F. (2001), "Knowledge spillovers and local innovation systems: A critical survey", Industrial \& Corporate Change, Vol. 10 No. 4, pp. 975- 1005.

Broekel, T. and Boschma, R. (2012), "Knowledge networks in the Dutch aviation industry the proximity paradox", Journal of Economic Geography, Vol. 12 No.2, pp. 409-433

Burt, R.S. (1997), “A note on social capital and network content”, Social Networks, Vol. 19 No. 4, pp. 355-373.

Burton, M.D., Sørensen, J. and Beckman, C. (2002), "Coming from good stock: Career histories and new venture formation", in Lounsbury, M. and Ventresca. M.J. (Eds.) 
Social Structure and Organizations Revisited, Research in the Sociology of Organizations Vol. 19, Elsevier (JAI Press), Oxford, pp. 229-262.

Cohen, W. and Levinthal, D. (1990), “Absorptive capacity: A new perspective on learning and innovation", Administrative Science Quarterly, Vol. 35 No.1, pp. 128-152.

Conceição, O., Fontes, M. and Calapez, T. (2012), "The commercialisation decisions of research-based spin-offs: Targeting the market for technologies", Technovation, Vol. 32 No. 1, pp. 43-56.

Cooke, P. (2006), "Global Bioregional Networks: A New Economic Geography of Bioscientific Knowledge”, European Planning Studies, Vol. 14 No. 9, pp. 1265-1285.

Dahl, M.S. and Pedersen, C.Ø.R. (2004), "Knowledge flows through informal contacts in industrial clusters: Myth or reality?”, Research Policy, Vol. 33 No.10, pp. 1673-1686.

Elfring, T. and Hulsink, W. (2003), "Networks in entrepreneurship: The case of hightechnology firms", Small Business Economics, Vol. 21 No. 4, pp. 409-422.

Egeln J., Gottschalk, S. and Rammer, C. (2004), "Location decisions of spin-offs from public research institutions", Industry and Innovation, Vol. 11 No. 3, pp. 207-223.

Fontes, M. (2005), “Distant networking: The knowledge acquisition strategies of 'out-cluster' biotechnology firms”, European Planning Studies, Vol. 13 No. 6, pp. 899-920.

Fontes, M. (2007), “Technological entrepreneurship and capability building in biotechnology", Technology Analysis and Strategic Management, Vol. 19 No.3, pp. $351-367$.

Fontes, M., Videira, C. and Calapez, T. (2013), "The impact of long term scientific mobility on the creation of persistent knowledge networks", Mobilities, Vol. 8 No3, pp. 440-465.

Gertler, M. and Levitte Y. (2005), "Local nodes in global networks: The geography of knowledge flows in biotechnology", Industry and Innovation, Vol. 12 No. 4, pp. 487507. 
Gilding, M. (2008), “The 'tyranny of distance': Biotechnology networks and clusters in the antipodes", Research Policy, Vol. 37 No. 6-7, pp. 1132-1144

Grandi A. and Grimaldi, R. (2003), "Exploring the networking characteristics of new venture founding teams: a study of Italian academic spin-offs", Small Business Economics, Vol. 21 No. 4, pp. 329-341.

Gulati, R. (1998), “Alliances and networks”, Strategic Management Journal, Vol. 19, 293317.

Healy, A. and Morgan, K. (2012), "Spaces of innovation: Learning, proximity and the ecological turn”, Regional Studies, 46 No. 8, pp. 1041-1053.

Hite, J. and Hesterly, W. (2001), "The evolution of firm networks: From emergence to early growth of the firm", Strategic Management Journal, Vol. 22 No. 3, pp. 275-286.

Huggins, R. and Johnston, A. (2010), "Knowledge flow and inter-firm networks: The influence of network resources, spatial proximity and firm size", Entrepreneurship \& Regional Development, Vol. 22 No. 5, pp. 457-484.

Kreiner, R. and Schultz, M. (1993), "Informal collaboration in R\&D. The formation of networks across organizations", Organization Studies, Vol. 14 No. 2, pp. 189-209.

Laursen, K., Reichstein, T. and Salter, A. (2011), "Exploring the effect of geographical proximity and university quality on university-industry collaboration in the United Kingdom”, Regional Studies, Vol. 45 No. 4, pp. 507-523.

Lemarié, S., Mangematin, V. and Torre, A. (2001), "Is the creation and development of biotech SMEs localized? Conclusions drawn from the French case", Small Business Economics, Vol. 17 No. 1-2, pp. 61-76.

Levitte, Y.M. and Bagchi-Sen, S. (2010), "Demographics, innovative outputs and alliance strategies of Canadian biotech firms", European Planning Studies, Vol. 18 No. 5, pp. $669-690$. 
Lorenz, E. (1999), "Trust, contract and economic cooperation", Cambridge Journal of Economics, Vol. 23 No. 3, pp. 301-315.

Lorenzen, M. (2007), "Social capital and localised learning: proximity and place in technological and institutional dynamics”, Urban Studies, Vol. 44 No.4, pp. 799-817.

Lowe, N.J. and Gertler, M. (2009), "Building on diversity: Institutional foundations of hybrid strategies in Toronto's life sciences complex”, Regional Studies, Vol. 43 No. 4, pp. 589-603.

Mangematin, V., Lemarié, S., Boissin, J.P., Catherine, D., Corolleur, F., Coronini, R. and Trommetter, M. (2002), "Development of SMEs and heterogeneity of trajectories: The case of biotechnology in France”, Research Policy, Vol. 32 No. 4, pp. 621-38.

McKelvey, M., Alm, H. and Riccaboni, M. (2003), "Does co-location matter for formal knowledge collaboration in the Swedish biotechnology-pharmaceutical sector",. Research Policy, Vol. 32 No. 3, pp. 483-501.

McMillan, G., Narin F. and Deeds D. (2000), “An analysis of the critical role of public science in innovation: The case of biotechnology", Research Policy, Vol. 29 No. 1, pp. $1-8$.

Moodysson, J., Coenen, L. and Asheim, B.T (2008), "Explaining spatial patterns of innovation: Analytical and synthetic modes of knowledge creation in the Medicon Valley life-science cluster", Environment and Planning A, Vol. 40 No. 5, pp. 10401056.

Murray, F. (2004), "The role of academic inventors in entrepreneurial firms: sharing the laboratory life", Research Policy, Vol. 33 No. 4, pp. 643-659.

Newbert, S.L. and Tornikoski, E.T. (2012), "Supporter networks and network growth: A contingency model of organizational emergence", Small Business Economics, Vol. 39 No. 1, pp. 141-159. 
Nooteboom, B., Van Haverbeke, W., Duysters, G., Gilsing, C. and van den Oord, A. (2007), “Optimal cognitive distance and absorptive capacity”, Research Policy, Vol. 36 No. 7, pp. 1016-1034.

Oettl, A. and Agrawal, A. (2008), "International labor mobility and knowledge flow externalities”, Journal of International Business Studies, Vol. 39, 1242-1260.

Østergaard, C. (2009), "Knowledge flows through social networks in a cluster: Comparing university and industry links", Structural Change \& Economic Dynamics, Vol. 20 No. 3, pp. 196-210.

Owen-Smith, J. and Powell, W. (2004), "Knowledge networks as channels and conduits: The effects of spillovers in the Boston biotechnology”, Organization Science, Vol. 15 No. 1, pp. 6-21

Ponds, R., van Oort, F.G. and Frenken, K. (2007), “The geographical and institutional proximity of research collaboration”, Papers in Regional Science, Vol. 86 No. 3, pp. 423-444.

Rutten, R., Westlund, H. and Boekema, F. (2010), "The spatial dimension of social capital”, European Planning Studies, Vol. 18 No. 6, pp. 863-871.

Saxenian, A. and Hsu, J.Y. (2001), “The Silicon Valley-Hsinchu Connection: Technical communities and industrial upgrading", Industrial \& Corporate Change, Vol. 10 No. 4, pp. 893- 920 .

Smith-Doerr, L. and Powell, W. (2005), "Networks and economic life", in Smelser, N.J. and Swedberg, R. (Eds.), The Handbook of Economic Sociology ( $2^{\text {nd }}$ edition), Princeton University Press, Princeton, pp. 379-402.

Sousa, C. and Fontes, M. (2014), "Building Innovation networks in science-based young firms: The selection of knowledge sources", International Journal of Entrepreneurship \& Small Business, Vol. 21 No. 3, pp. 370-390. 
Stuart, T. and Sorenson, O. (2003), “The geography of opportunity: Spatial heterogeneity in founding rates and the performance of biotechnology firms", Research Policy, Vol. 32 No. 2, pp. 229-253.

Stuart, T.E., Ozdemir, S.Z. and Ding, W.W. (2007), "Vertical alliance networks: The case of university-biotechnology-pharmaceutical alliance chains”, Research Policy, Vol. 36 No. 4, pp. 477-98.

Torre, A. and Rallet, A. (2005), "Proximity and localization", Regional Studies, Vol. 39 No. 1, pp. 47-59.

Torre, A. (2008), "On the role played by temporary geographical proximity in knowledge transmission”, Regional Studies, Vol. 42 No. 6, pp. 869-889.

Trippl, M., Tödtling, F. and Lengauer, L. (2009), "Knowledge sourcing beyond buzz and pipelines: Evidence from the Vienna software sector", Economic Geography, Vol. 85 No. 4, pp. 443-462.

Vale, M. and Carvalho, L. (2012), "Knowledge networks and processes of anchoring in Portuguese biotechnology”, Regional Studies, Vol. 47 No. 7, pp. 1018-1033.

Vissers, G. and Dankbaar, B. (2013), "Knowledge and proximity", European Planning Studies, Vol. 21 No. 5, pp. 700-721

Williams, A., Baláz, V. and Wallace, C. (2004), “International labour mobility and uneven regional development in Europe: Human capital, knowledge and entrepreneurship", European Urban and Regional Studies, Vol. 11 No. 1, pp. 27-46.

Whittington, K., Owen-Smith, J. and Powell, W. (2009), "Networks, propinquity and innovation in knowledge-intensive industries", Administrative Science Quarterly, Vol. 54 No. 1, pp. 90-122. 
Zucker, L., Darby M. and Armstrong J. (2002), “Commercializing knowledge: University science, knowledge capture and firm performance in biotechnology", Management Science, Vol. 48 No. 1, pp. 138-153.

Table 1 - Location of knowledge sources: relative importance of geographical proximity

\begin{tabular}{lcc}
\hline & Frequency & Relative frequency \\
\hline Local ties & 37 & $36 \%$ \\
National ties & 25 & $24 \%$ \\
International ties & 41 & $40 \%$ \\
\hline Total & 103 & $100 \%$ \\
\hline
\end{tabular}

Table 2 - Origin of the ties: relative importance of relational proximity

\begin{tabular}{lcc}
\hline & Frequency & Relative frequency \\
\hline Trajectory ties & 43 & $42 \%$ \\
Intentional ties & 60 & $58 \%$ \\
\hline Total & 103 & $100 \%$ \\
\hline
\end{tabular}

Table 3 - Importance of different types of proximity

\begin{tabular}{|c|c|c|c|}
\hline & \multicolumn{2}{|c|}{ Spatial location of actors } \\
\hline & & Extra-local ties & Local ties \\
\hline \multirow[t]{2}{*}{ Origin of ties } & Trajectory ties & $\begin{array}{c}\text { Ties with relational proximity } \\
\text { only } \\
\mathbf{1 8 . 4 \%}\end{array}$ & $\begin{array}{c}\text { Ties with relational AND } \\
\text { geographical proximity } \\
\mathbf{2 3 . 3 \%}\end{array}$ \\
\hline & Intentional ties & $\begin{array}{c}\text { Distant ties (in geographical } \\
\text { AND relational terms) } \\
\mathbf{4 5 . 6 \%}\end{array}$ & $\begin{array}{c}\text { Ties with geographical } \\
\text { proximity } \\
\mathbf{1 2 . 6 \%} \\
\end{array}$ \\
\hline
\end{tabular}

Table 4 - Nature of the tie 


\begin{tabular}{lcc}
\hline & Frequency & Relative frequency \\
\hline Formal ties & 45 & $44 \%$ \\
Informal ties & 40 & $39 \%$ \\
Ties both formal \& informal & 18 & $17 \%$ \\
\hline Total & 103 & $100 \%$ \\
\hline
\end{tabular}


Table 5 - Proximit(ies) and the nature of the tie

\begin{tabular}{lcccc}
\hline & Formal & Informal & $\begin{array}{c}\text { Formal \& } \\
\text { Informal }\end{array}$ & Total \\
\hline Ties with relational \& geographical proximity & $4 \%$ & $67 \%$ & $29 \%$ & $100 \%$ \\
Ties with relational proximity only & $11 \%$ & $68 \%$ & $21 \%$ & $100 \%$ \\
Ties with geographical proximity only & $54 \%$ & $8 \%$ & $38 \%$ & $100 \%$ \\
Distant ties (geographical \& relational) & $75 \%$ & $21 \%$ & $4 \%$ & $100 \%$ \\
\hline
\end{tabular}

Table 6 - Correlation between forms of proximity and nature of the tie

\begin{tabular}{llll}
\hline & Formal & Informal & $\begin{array}{c}\text { Formal \& } \\
\text { Informal }\end{array}$ \\
\hline Ties with relational \& geographical proximity & $-0.439^{* *}$ & $0.315^{* *}$ & 0.170 \\
Ties with relational proximity only & $-0.318^{* *}$ & $0.289^{* *}$ & 0.045 \\
Ties with geographical proximity only & 0.078 & $-0.243^{* *}$ & $0.210^{*}$ \\
Distant ties (geographical \& relational) & $0.568^{* *}$ & $-0.330^{* *}$ & $-0.319^{* *}$ \\
\hline * significant at the 5\% level (2-tailed); ** significant at the 1\% level (2-tailed) & &
\end{tabular}

Figure 1 - Analytical framework

\begin{tabular}{|c|c|c|c|}
\hline \multirow{4}{*}{ 동 } & 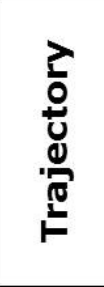 & $\begin{array}{c}\text { Ties with relational } \\
\text { proximity only } \\
\text { Informal } \\
\text { Formal }\end{array}$ & $\begin{array}{c}\text { Ties with relational \& } \\
\text { geographical proximity } \\
\text { Informal }\end{array}$ \\
\hline & 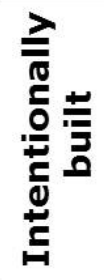 & $\begin{aligned} & \\
\text { Distant ties } & \\
\text { Informal } & \text { For }\end{aligned}$ & $\begin{array}{c}\text { Ties with geographical } \\
\text { proximity only } \\
\vdots \\
\text { Informal }\end{array}$ \\
\hline & & Other location & Co-location \\
\hline & & & of source \\
\hline
\end{tabular}

Figure 2 - Clusters and forms of proximity 


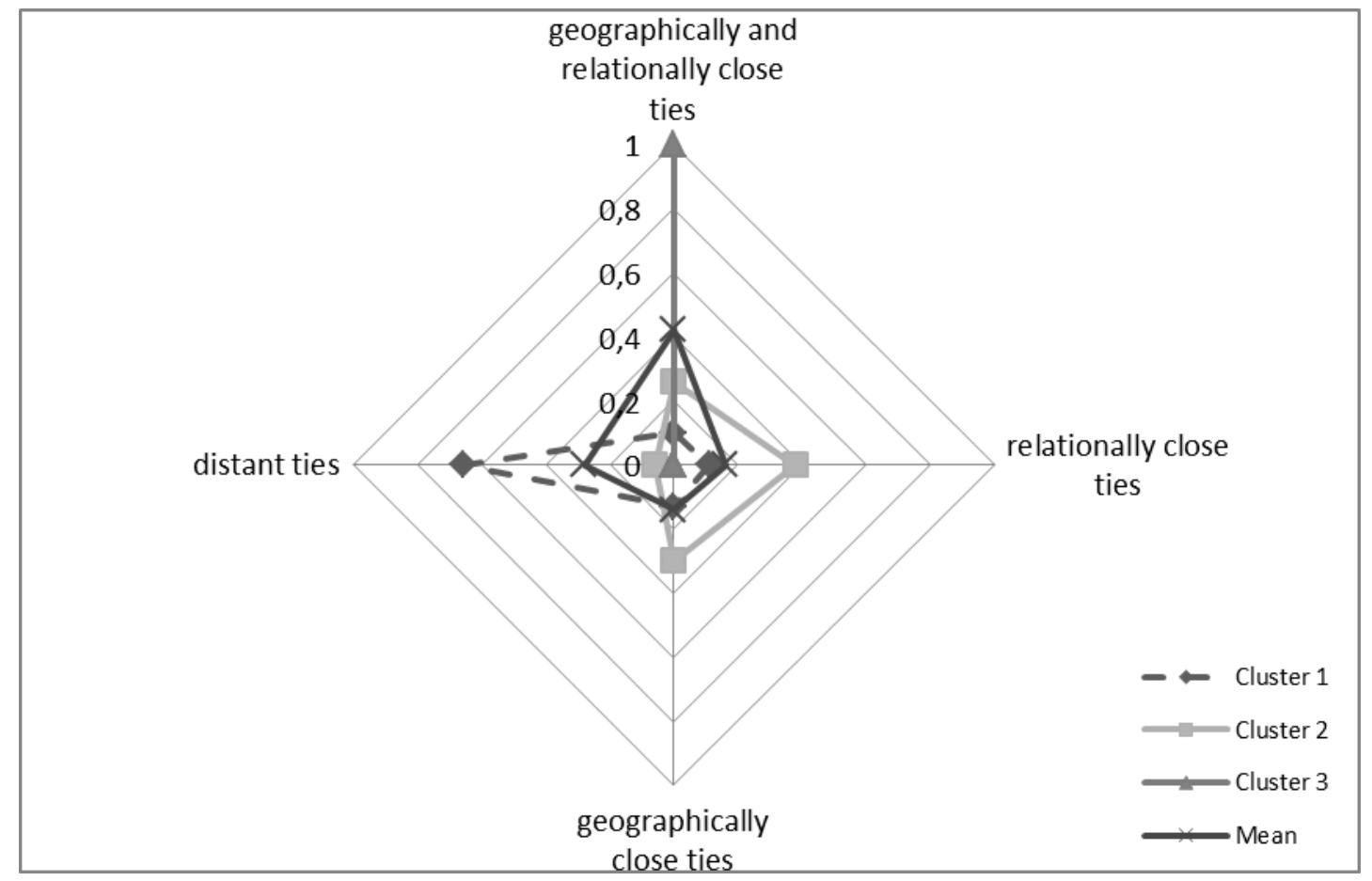

